\title{
Pengetahuan Remaja Putri Terhadap Dampak Pernikahan Dini
}

\section{Knowledge Adolescent Girls With The Impact Of The Early Marriage}

\author{
Vika Nurhaliza1, Iroma Maulida, Nora Rahmanindar \\ Diploma III Kebidanan, Politeknik Harapan Bersama Tegal \\ 1Email : vikanurhaliza14@ gmail.com
}

\begin{abstract}
ABSTRAK
Menurut Survei Data Kependudukan Indonesia (SDKI), jumlah kasus pernikahan dini di Indonesia mencapai 50 juta penduduk dengan rata-rata usia perkawinan 19,1 tahun. Kehamilan remaja akan meningkatkan risiko kematian 2-4 kli lebih tinggi dibandingkan hamil pada usia > 20 tahun karena akan membahayakan kesehatan ibu dan bayinya, seperti kematian ibu dan bayi, risiko komplikasi kehamilan, komplikasi persalinan, terjadinya perdarahan post partum, risiko terjadinya abortus, berat badan lahir rendah (BBLR) dan kanker serviks adalah kasus yang dialami oleh wanita yang menikah dini. Penelitian ini bertujuan untuk mengetahui Gambaran Pengetahuan Remaja Terhadap Dampak Pernikahan dini di Desa Bojong Kecamatan Bojong Kabupaten Tegal Tahun 2019. Rancangan dan jenis penelitian ini adalah penelitian deskriptif melalui pendekatan cross sectional dengan teknik pengambilan sampel purposive sampling. Populasinya remaja putri usia 15-17 tahun sebanyak 350 orang dan didapatkan78 responden. Hasil penelitian ini di dapat adalah remaja putri yang diwawancarai oleh peneliti sebagian besar berumur 16 tahun sebanyak 47.4\%, berpendidikan Sekolah Menengah Pertama (SMP) sebanyak $55.1 \%$ dan tidak bekerja sebanyak $75.6 \%$. Gambaran pengetahuan remaja putri terhadap dampak pernikahan dini sebagian besar termasuk dalam kategori baik yaitu sebanyak $91 \%$.
\end{abstract}

Kata Kunci : Remaja Putri, Pernikahan Dini.

ABSTRACT

According to the Indonesia Population Data Survey (IDHS), the number of cases of early marriage in Indonesia reaches 50 million people with an average marriage age of 19.1 years. Teen pregnancy will increase the risk of death 2-4 kli higher than pregnancy at the age of $>20$ years because it will endanger the health of mother and baby, such as maternal and infant mortality, risk of pregnancy complications, delivery complications, post partum hemorrhage, risk of abortion, severe low birth weight $(L B W)$ and cervical cancer are cases experienced by women who marry early. This study aims to determine the Description of Adolescent Knowledge Against the Impact of Early Marriage in Bojong Village, Bojong Subdistrict, Tegal Regency in 2019. The design and type of this research was descriptive research through a cross sectional approach with a purposive sampling technique. The population was young women aged 15-17 years as many as 350 people and found 78 respondents. The results of this study can be obtained by young women interviewed by researchers mostly aged 16 years as many as 47.4\%, educated junior high school (SMP) as much as $55.1 \%$ and not working as much as $75.6 \%$. The description of adolescent girls' knowledge of the effects of early marriage was mostly included in the good category at $91 \%$.

Keywords : Young Women, Early Marriage.

PENDAHULUAN

Berdasarkan Survei Data

Kependudukan Indonesia (SDKI), di

beberapa daerah didapatkan bahwa sepertiga dari jumlah pernikahan terdata dilakukan oleh pasangan usia di bawah 16 tahun. Jumlah kasus pernikahan dini di Indonesia mencapai 50 juta penduduk 
dengan rata-rata usia perkawinan 19,1 tahun. Di Jawa Timur, Kalimantan Selatan, Jambi, dan Jawa Barat, angka kejadian pernikahan dini berturut-turut $39,4 \%, \quad 35,5 \%, 30,6 \%$, dan $36 \%$. Bahkan di sejumlah pedesaan, pernikahan seringkali dilakukan segera setelah anak perempuan mendapat haid pertama. (Sari Pediatri, 2009).

Koalisi Perempuan Indonesia (KPI) mendesak dikeluarkan peraturan gubernur (pergub) tentang penghentian pernikahan anak di Jateng. Usulan itu sebagai tindak lanjut banyaknya perempuan menikah pada usia di bawah umur. Tahun 2017 pernikahan anak di Jawa Tengah paling tinggi di Brebes, Pekalongan dan Grobogan. Pada tahun 2017 sendiri banyak warga Jateng mengusulkan menikah di bawah usia 16 tahun. Padahal berdasar pasal 7 ayat 1 Undang-undang Nomor 1 tahun 1975 tentang perkawinan bahwa ketentuan batas pernikahan untuk perempuan yakni 16 tahun dan 19 untuk pria.

\section{METODE PENELITIAN}

Rancangan dan jenis penelitian ini menggunakan survey deskriptif dengan pendekatan crosssectional, populasi dalam penelitian ini adalah remaja putri usia 15-17 di Desa Bojong tahun 2019 berjumlah 78 orang dilaksanakan pada bulan April 2019. Teknik pengambilan sampel menggunakan teknik purposive sampling yaitu sejumlah 78 remaja putri. Data yang diperoleh akan diolah secara analisis univariate.

\section{HASIL DAN PEMBAHASAN}

Analisis Univariat

Responden kategori dalam penelitian ini adalah umur, pendidikan dan pekerjaan.

Tabel 1 Karakteristik Responden Penelitian.

\begin{tabular}{lcc}
\hline \multicolumn{1}{c}{ Karakteristik } & Frekuensi & \% \\
\hline Umur & & \\
15 tahun & 23 & 29.5 \\
16 tahun & 37 & 47.4 \\
17 tahun & 18 & 23.1 \\
& & \\
Pendidikan & & \\
Sekolah Dasar & 35 & 44.9 \\
Sekolah Menengah Pertama & 43 & 55.1 \\
Sekolah Menengah Atas & 0 & 0 \\
Perguruan Tinggi & 0 & 0 \\
& & \\
Pekerjaan & & \\
Bekerja & 59 & 75.6 \\
Tidak Bekerja & 19 & 24.4 \\
\multicolumn{1}{c}{ Total } & & \\
& & 100 \\
\hline
\end{tabular}

Berdasarkan tabel 1 di atas dapat dilihat bahwa sebagian besar responden yang berumur 16 tahun yaitu sebanyak 37 orang (47.4\%). Dan yang paling sedikit responden berumur 17 tahun sebanyak 18 orang (23.1\%).Sebagian besar responden yang berpendidikan Sekolah Menengah Pertama sebanyak 
43 orang $(55.1 \%)$ dan yang paling sedikit responden yang berpendidikan Sekolah Dasar sebanyak 35 orang (44.9\%). Responden yang tidak bekerja sebanyak 59 orang $(75.6 \%)$ dan yang paling sedikit responden yang bekerja sebanyak 19 orang (24.4\%).

Tabel 2 Pengetahuan Remaja Putri Terhadap Dampak Pernikahan dini.

\begin{tabular}{|c|c|c|c|c|c|c|}
\hline \multirow{3}{*}{ Karakteristik } & \multicolumn{6}{|c|}{ Pengetahuan } \\
\hline & \multicolumn{2}{|l|}{ Baik } & \multicolumn{2}{|c|}{ Cukup } & \multicolumn{2}{|l|}{ Total } \\
\hline & Frekuensi & $\%$ & Frekuensi & $\%$ & Frekuensi & $\%$ \\
\hline \multicolumn{7}{|l|}{ Umur } \\
\hline 15 tahun & 19 & 82.6 & 4 & 17.4 & 23 & 100 \\
\hline 16 tahun & 35 & 94.4 & 2 & 5.6 & 37 & 100 \\
\hline 17 tahun & 17 & 94.6 & 1 & 5.4 & 18 & 100 \\
\hline \multicolumn{7}{|l|}{ Pendidikan } \\
\hline Sekolah Dasar & 30 & 85.7 & 5 & 14.3 & 35 & 100 \\
\hline Sekolah Menengah Pertama & 41 & 95.3 & 2 & 4.7 & 43 & 100 \\
\hline \multicolumn{7}{|l|}{ Pekerjaan } \\
\hline Tidak Bekerja & 53 & 89.8 & 6 & 10.2 & 59 & 100 \\
\hline Bekerja & 18 & 94.7 & 1 & 5.3 & 19 & 100 \\
\hline Total & \multicolumn{2}{|l|}{71} & \multicolumn{2}{|l|}{7} & \multicolumn{2}{|l|}{78} \\
\hline
\end{tabular}

Berdasarkan tabeldi atas dapat dilihat bahwa sebagian besar responden berpengetahuan baik sebanyak 71 remaja putri (91\%). Pengetahuan baik paling banyak yaitu remaja umur 17 tahun sebanyak 17 responden (94.6\%), pengetahuan cukup paling banyak yaitu remaja umur 15 tahun sebanyak 4 responden (17.4\%) Kemungkinan ada hubungan antara umur remaja putri dengan pengetahuan remaja putri tentang dampak pernikahan dini di Desa Bojong Kecamatan Bojong Kabupaten Tegal.

Menurut Huclock yang dikutip Wawan dkk (2011), semakin cukup umur, tingkat kematangan dan kekuatan seseorang akan lebih matang dalam berfikir dan bekerja. Dari segi kepercayaan masyarakat seseorang yang lebih dewasa dipercaya dari orang yang belum tinggi kedewasaannya. Hal ini sebagai pengalaman dan kematangan jiwa. Hal ini menunjukkan kesesuaian antar umur dan pengetahuan, semakin tua umur seseorang semakin matang pola pikirnya. Ini dikarenakan banyaknya pengalaman yang didapat dan kematangan jiwa individu tersebut sehingga informasi yang didapat lebih mudah dicerna daripada yang berumur muda.

Menurut hasil penelitian yang dilakukan Eddy Fadlyana dan Shinta Larasaty dapat disimpulkan bahwa kehamilan pada usia kurang dari 17 tahun meningkatkan risiko komplikasi medis, baik pada ibu maupun pada 
anak. Kehamilan di usia yang sangat muda ini ternyata berkorelasi dengan angka kematian dan kesakitan ibu.

Dilihat bahwa pengetahuan baik paling banyak yaitu responden yang sekolah menengah pertama sebanyak 41 responden $(95.3 \%)$, pengetahuan cukup paling banyak yaitu sekolah dasar sebanyak 5 responden $(14.3 \%)$. Kemungkinan ada hubungan antara pendidikan remaja putri dengan pengetahuan remaja putri tentang dampak pernikahan dini di Desa Bojong Kecamatan Bojong Kabupaten Tegal.

Pendidikan diperlukan untuk mendapatkan informasi, misalnya halhal yang menunjang kesehatan sehingga dapat meningkatkan kualitas hidup. Tingkatan pendidikan menunjukkan perubahan korelasi positif dengan terjadinya perilaku positif yang meningkat (Suharso dkk, 2012). Dari berbagai penelitian didapatkan bahwa terdapat korelasi antara tingkat pendidikan dan usia saat menikah, semakin tinggi usia anak saat menikah maka pendidikan anak relative lebih tinggi dan demikian pula sebaliknya. Pernikahan di usia dini menurut penelitian UNICEF tahun 2016 tampaknya berhubungan pula dengan derajat pendidikan yang rendah.
Menunda usia pernikahan merupakan salah satu cara agar anak dapat mengeyam pendidikan lebih tinggi (Fadlyana, 2009).

Menurut YB Mantra yang dikutip Wawan dkk (2011), pendidikan dapat mempengaruhi seseorang termasuk juga perilaku seseorang akan pola hidup terutama dalam memotivasi untuk sikap berperan serta dalam pembangunan. Pada umumnya makin tinggi pendidikan seseorang makin mudah menerima informasi. Hal ini menunjukkan adanya kesesuaian antara pendidikan dengan cara seseorang menangkap dan mencerna informasi yang diperoleh.

Menurut Wawan dkk (2011), pekerjaan bukanlah sumber kesenangan, tetapi lebih banyak cara mencari nafkah yang membosankan, berulang dan banyak tantangan. Sedangkan pekerjaan umumnya merupakan kegiatan yang menyita waktu. Hal ini menunjukkan adanya ketidaksesuaian antara pekerjaan dengan pengetahuan, karena bekerja mempunyai banyak tantangan sehingga otak terbiasa berpikir sehingga mudah mencerna hal-hal baru dan disaring dari pengalaman yang didapat.

Menurut hasil penelitian yang dilakukan Eddy Fadlyana dan Shinta 
Larasaty dapat disimpulkan bahwa motif ekonomi, harapan tercapainya keamanan sosial dan finansial setelah menikah menyebabkan banyak orangtua menyetujui pernikahan anak ini seringkali dilandasi pula oleh ketakutan akan terjadinya kehamilan diluar nikah akibat pergaulan bebas. Dari hasil penelitian tersebut dapat disimpulkan bahwa remaja yang mempunyai motif ekonomi rendah (tidak bekerja), berpeluang menikah usia dini untuk menopang hidupnya dari penghasilan suami (Pediatri, 2009).

\section{SIMPULAN DAN SARAN}

Berdasarkan atas hasil penelitian yang telah dilakukan, maka dapat ditarik kesimpulan bahwa pengetahuan remaja putri terhadap dampak pernikahan dini sebagian besar termasuk dalam kategori baik yaitu sebanyak $91 \%$, yang terdapat pada katagori remaja umur 17 tahun yaitu sebanyak 17 responden (94.6\%), pendidikan Sekolah Menengah Pertama (SMP) sebanyak 41 responden (95.3\%), dan tidak bekerja sebanyak 53 responden $(89.8 \%)$.

Diharapkan dengan hasil
penelitian ini dapat digunakan untuk

memberikan informasi, pengetahuan dan meningkatkan mutu pelayanan sehingga tercipta remaja sehat yang dapat mencegah terjadinya pernikahan di usia dini, dan dapat menambah wawasan bagi para pembaca, sebagai referensi atau bahan pustaka yang digunakan dalam melakukan pengembangan ilmu pengetahuan atau digunakan dalam penelitian berikutnya, serta dapat digunakan untuk memberikan pengetahuan yang lebih baik kepada remaja putri dan orangtua agar mengetahui dampak pernikahan dini dan bisa menunda keinginan untuk menikah dini sehingga bisa terciptanya remaja putri yang lebih berkualitas.

\section{DAFTAR PUSTAKA}

Imron, 2012. Pendidikan Kesehatan Reproduksi

Jogjakarta: Ar-Ruzz Media.

Erfandi,2009. Pengetahuan. Perilaku. Jakarta: Penebar Plus.

Fadlyana, Eddy dan Shinta Larasaty, Agustus 2009, "Pernikahan Usia Dini dan Permasalahannya". Volume 11, No. 2.

Kumala Sari, 2012. Kesehatan Reproduksi Untuk Mahasiswa Kebidanan dan Keperawatan. Jakarta: Salemba Medika.

Wawan, A dan Dewi M. 2011. Teori dan Pengukuran Pengetahuan, Sikap dan Perilaku Manusia. Yogyakarta: Nuha Medika. 